\title{
Effect of ph on the stability of red beet extract (Beta vulgaris 1.) microcapsules produced by spray drying or freeze drying
}

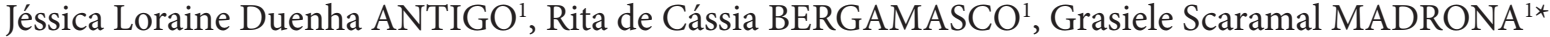

\begin{abstract}
Red beets is rich in phenolic acids and has high antioxidant capacity, and can be used to produce a natural dye. This study evaluated the effect of $\mathrm{pH}$ (3 to 6) on the stability of red beet extract microcapsules, dried by freeze drying and spray drying and stored at room temperature. The microcapsules were produced using a combination of maltodextrin and xanthan gum as encapsulating agents and stored for 7 days. For all evaluated microcapsules, a degradation of betanin was observed, however, that degradation was independent of $\mathrm{pH}$, with the exception of the sample with maltodextrin and dried by spray drying. The freeze dried products showed lower degradation constants and higher half-life $\left(\mathrm{t}_{1 / 2}\right)$ when comparing with the spray dried samples. The microcapsules containing maltodextrin and xanthan gum, dried by spray drying, showed the highest change in the content of phenolic compounds after storage for 7 days. The color parameters showed a reduction for $\mathrm{a}^{*}$, and increase in $\mathrm{b}^{*}$ and $\mathrm{L}^{*}$, for all samples during the storage time. In general, the microcapsules produced using maltodextrin and xanthan gum, and dried by freeze dryer, showed higher stability in terms of betanin content, phenolic compounds and color parameters during storage at different $\mathrm{pHs}$.
\end{abstract}

Keywords: encapsulation; natural dye; betanin; phenolic compounds; maltodextrin; xanthan gum.

Practical Application: The best drying parameters and encapsulating agent for the natural beet dye were defined for foods with different $\mathrm{pHs}$.

\section{Introduction}

The red beet root (Beta vulgaris L.) is a traditional vegetable that is widely consumed in several countries. The caloric value is moderate, but it is a rich source of fiber and sugars (Straus et al., 2012). Consumption of red beet, which is rich in phenolic acids and has high antioxidant capacity, can help protect against age-related diseases (Ravichandran et al., 2013).

The natural dye present in red beet is betalain, which contains two groups of pigments: betacyanins (red-violet) and betaxanthin (yellow), and this pigments together result in a number of varieties of red color. The betacyanin present mainly in the roots of red beets is known as betanin (Nemzer et al., 2011).

The stability of betanin depends directly on its $\mathrm{pH}$, which ranges from 3 to 7 , with the optimum pH being between 4 and 5. Its spectrum ranges from pink to red. It is unstable in the presence of light and oxygen, and is degraded when subjected to high temperatures (Huang \& Von Elbe, 1987). According to Serris \& Biliaderis (2001), the possibility of the betanin regeneration at 30,40 and $50^{\circ} \mathrm{C}$ is minimal. This is an important factor, once the regeneration of betanin can interfere the kinetics degradation.

Natural dyes generally have higher costs and exhibit a lower stability under storage and processing conditions when compared with artificial dyes (Cardoso-Ugarte et al., 2014). One way to improve the stability of natural dyes is the encapsulation process, which creates a barrier between the core material and the environment. This barrier is formed by the supporting material (encapsulating agent) which protects the encapsulated material, making the final product more stable (Janiszewska, 2014).

There are various encapsulating agents, such as polysaccharides, lipids and proteins, and the most widely used is maltodextrin, due to the low cost (Saénz et al., 2009). Furthermore, some gums, such as xanthan gum, can also be used in combination with maltodextrin during the encapsulation process, for increase the encapsulation yield. Ravichandran et al. (2014) found that the microencapsulation of betalain with maltodextrin associated with xanthan gum $(0.5 \%)$ showed better stability and an increase of up to $65 \%$ in betanin content when compared to maltodextrin encapsulation alone.

One of the most widely used techniques for microencapsulation is spray drying, which is the atomizing of an emulsion or suspension containing the encapsulated material and the encapsulant agent in a drying chamber with hot air circulation. The contact of the solution with hot air causes the water evaporation, resulting in the production of the microcapsules (Laohasongkram et al., 2011). Another technique that can be used is freeze drying, which consists in the frozen of the solution containing the encapsulating agent and the encapsulated material, followed by drying sublimation under vacuum, and the change in ice occurs directly from the solid in vapor without becoming liquid (Kumar et al., 2011). 
The objective of this study was to encapsulate the natural dye of red beets in a combination of maltodextrin and xanthan gum, using freeze drying and spray drying techniques, and to evaluate the stability of the resulting microcapsules at different $\mathrm{pHs}$.

\section{Materials and methods}

The red beet used in this research was acquired in the local market of the city of Maringa-Brazil, which has latitude $23^{\circ} 25^{\prime} 31^{\prime \prime S}$ and longitude $51^{\circ} 56^{\prime} 19^{\prime}$ " W, during the period from July to November.

The maltodextrin (DE 10) was provided by Cargill (São Paulo-Brazil) and xanthan gum was purchased from Doce Aroma (São Paulo-SP). All reagents used in the study were of analytical grade.

\subsection{Extraction of betanin}

The beets were washed, sanitized (using 200 ppm of active chlorine during $15 \mathrm{~min}$ ) and sliced. The juice was extracted with a centrifugal Turbo Juicer CF-06 (Mondial) and filtered through filter paper.

\subsection{Processing of the microcapsules}

The encapsulating agents were added to the red beet juice in a quantity of $30 \mathrm{~g}$ dry material/100 g total matter. Two solutions were prepared: one containing only maltodextrin and another containing maltodextrin (99.5\%) and xanthan gum $(0.5 \%)$. The solutions were dried by spray drying or freeze drying.

For microencapsulation by spray drying, the solutions were dried on a mini spray drier (LM brand; model MSD 1.0). The drying conditions were: nozzle diameter of $0.7 \mathrm{~mm}$; drying air inlet temperature of $150{ }^{\circ} \mathrm{C}$ and outlet $90{ }^{\circ} \mathrm{C}$; atomization pressure: 0.08 to 0.14 bar; average flow drying air of $3.8 \mathrm{~m}^{3} / \mathrm{h}$; average feed flow rate $0.6 \mathrm{~L} / \mathrm{h}$. The powders collected were stored in plastic bags with nylon polyethylene thermosoldable for later use.

For microencapsulation by freeze drying, the samples were frozen for 48 hours at $-10^{\circ} \mathrm{C}$. The samples were subsequently dried by freeze drying for 2 days $\left(-36^{\circ} \mathrm{C}, 1.09 \mathrm{~Pa}\right)$ to ensure complete drying of the product (L108 freeze dryer, Liobras). The final product was stored in plastic bags with nylon polyethylene thermosoldable for later use.

The dried powders were named: powder containing maltodextrin as the encapsulating agent and dried by spray drying (MAS), powder containing maltodextrin and xanthan gum and dried by spray drying (MXS), powder containing maltodextrin as the encapsulating agent and dried by freeze drying (MAL), and powder containing maltodextrin and xanthan gum and dried by freeze drying (MXL).

\subsection{Betanin stability at different pHs}

Solutions containing the microcapsules (MAL MXL, MAS and MXS) (10\% w/v) were prepared in buffers at $\mathrm{pH} 3,4,5$ and 6. Potassium sorbate (5\%) was added to each of these solutions to prevent contamination by microorganisms. Sodium acetate was used as the buffer for $\mathrm{pH} 3$ to 5 solutions, and sodium phosphate was used for pH 6 (Gandía-Herrero et al., 2009). The buffer solutions of microcapsules were storage in BOD (Biochemical oxygen demand) chamber for 7 days, at a constant temperature of $30{ }^{\circ} \mathrm{C}$. Periodic measurements of betanin content, phenolic compounds and color parameters of buffered solutions were determined.

\subsection{Quantification of betanin}

The betanin content in the microcapsules was determined according to the methodology of Stintzing et al. (2005). The color degradation was monitored on time zero (control) and 1, 3, 4 and 7 days. The betanin degradation kinetics were verified by periodic absorption measurements of buffer solutions of microcapsules at $538 \mathrm{~nm}$, at $30^{\circ} \mathrm{C}$.

To evaluate the reaction kinetics during the dye storage in buffer solutions, we tested first order kinetic models. Previous research demonstrated that the degradation of natural dyes such as betanin follows first order kinetics during storage (Serris \& Biliaderis, 2001; Bustos-Garza et al., 2013). The color degradation can be calculated using Equation 1 .

$$
\frac{d C}{d t}=-k C_{0}
$$

Where: $\mathrm{C}$ is the remaining concentration; $\mathrm{C}_{0}$ is the initial concentration of dye; $\mathrm{t}$ is the time interval between $\mathrm{C}_{0}$ and $\mathrm{C} ; \mathrm{k}$ is the degradation constant of first order (1/time). In plotting concentration (-ln C) versus time, the conversion constant $(\mathrm{k})$ is simply the slope of the line.

The half-life $\left(t_{1 / 2}\right)$ for the reaction is the time required for the quantity of betanin to be reduced by half its initial value. The half-life, which, according to Kirca \& Cemeroglu (2003), is directly related to the speed constant for a first order reaction, is described by Equation 2.

$t_{1 / 2}=-\frac{\ln (0.5)}{k}$

\subsection{Analysis of total phenolic compounds}

The total phenolic content was determined by spectrophotometry, following the Folin-Ciocalteu method, with the same modifications of Ruiz-Gutiérrez et al. (2014). Measurements were performed in triplicate using a gallic acid curve as a standard. It was used a spectrophotometer model 700S of the brand FEM and wavelength $765 \mathrm{~nm}$. Results were expressed in mg of gallic acid equivalents (GAE)/100 g powder.

\subsection{Color analysis}

Color was evaluated using a portable colorimeter CR400 Konica Minolta ${ }^{\circledast}$ with integrating sphere and $3^{\circ}$ of viewing. The color parameters were measured using a CIEL $\mathrm{a}^{\star} \mathrm{b}^{\star}$ system. Hue angle $(h)$ was calculated according to the Equation 3. 


$$
h=\tan ^{-1}\left(\frac{b^{*}}{a^{*}}\right)
$$

\subsection{Statistical analysis}

Data were expressed as mean \pm standard deviation, after tests of normality and homogeneity, data were underwent to analysis of variance (ANOVA) and correlation analysis, with Statistica software version 8.0 (StatSoft, Inc., Tulsa, OK, USA). We adopted the significance level of $5 \%$ for rejection of the null hypothesis $(\mathrm{p}<0.05)$ for the Tukey test. The Pearson correlation coefficient is a measure of the degree of linear relationship between two variables and this quantitative test was used to determine the correlation between the betanin content, color parameters and phenolic compounds content of beet extract microcapsules.

\section{Results and discussion}

\subsection{Quantification of betanin}

The degradation of betanin, evaluated at different $\mathrm{pHs}$, followed first order kinetics, as previously demonstrated in the literature (Serris \& Biliaderis, 2001; Bustos-Garza et al., 2013; Cano-Higuita et al., 2015). The degradation constant and half-life of the microcapsules, stored in different buffer solutions, are presented in Table 1.

Samples MXS, MAL and MXL present no significant differences in the degradation constant at the evaluated $\mathrm{pHs}$ (Table 1). As the stability of betanin is $\mathrm{pH}$ dependent, being more stable between pH 4 and 5 (Huang \& Von Elbe, 1987), this result shows the betanin encapsulation efficiency in maltodextrin and xanthan gum, where a dye degradation was observed, but this degradation is independent of $\mathrm{pH}$ of the solution.

The degradation constants for microcapsules containing maltodextrin dried by spray drying (MAS), differed significantly depending on $\mathrm{pH}$, wherein the $\mathrm{pH} 3$ and 4 did not differ, but differed in relation to $\mathrm{pH} 5$ and 6, with the lowest values observed at $\mathrm{pH} 3$ and 4 . It can be explained because maltodextrin is an encapsulating agent widely used in encapsulation of active materials by spray drying; however, it has low emulsifying capacity, and the incorporation of other encapsulating agents, such as xanthan gum, can improve this capability (Poshadri \& Kuna, 2010). The use of xanthan gum in the formation of the microcapsules increased the stability of betanin, the sample dried in spray drying presented lower constant degradation at $\mathrm{pH} 3$ and 4; and no difference was observed for the freeze drying method.

When the methods of drying were compared, freeze drying produced lower degradation constants for all evaluated $\mathrm{pHs}$, as compared to spray drying. The microcapsules obtained by spray drying and freeze drying have different structures, due to the drying mechanisms. While the spray drying the homogenization of solution before drying has an important role in encapsulation efficiency, ensuring that the material is completely entrapped in the matrix, and not permitting a significant amount of this component in the particle surface, in the freeze drying homogenization has little influence on microcapsule structure (Cano-Higuita et al., 2015). In our study, spray drying produced higher degradation constants compared with freeze drying, probably because there were large quantities of betanin on the microcapsules surface produced by this technique.

In a study by Ravichandran et al. (2014), the authors observed a $21 \%$ increase in the stability of microcapsules of red beet extract dried by spray drying and a $65 \%$ increase for the microcapsules dried by freeze drying, when the combination of maltodextrin and xanthan gum $(0.5 \%)$ was used as an encapsulating, as compared to the use of maltodextrin alone.

It was observed (after 7 storage days in $\mathrm{pH} 6$ ) that the sample MXS decreased $44.9 \%$ in constant degradation when compared to the MAS sample. The freeze dried sample MXL this reduction was around $19.6 \%$ compared to MAL, but statistically $(\mathrm{p}<0.05)$ the freeze dried samples did not differ.

The half-life of the microcapsules was also calculated and ranged from 3.2 to 6.3 days for the spray drying and 5.5 to 7.6 days for freeze drying, being higher in this last drying methodology. Bustos-Garza et al. (2013) evaluated the microencapsulation of astaxanthin from Haematococcus pluvialis at $25^{\circ} \mathrm{C}$, with maltodextrin and arabic gum (50:75), and dried by a spray dryer

Table 1. Degradation constant $(\mathrm{k})$ and half-life $\left(\mathrm{t}_{1 / 2}\right)$ of microcapsules stored in different buffer solutions.

\begin{tabular}{|c|c|c|c|c|}
\hline \multirow[t]{2}{*}{ Sample } & \multicolumn{4}{|c|}{$\begin{array}{c}\mathrm{k} \times 10^{3}\left(\text { day }^{-1}\right) \\
\text { Time of half-life }(\text { days })\end{array}$} \\
\hline & pH 3 & pH 4 & pH 5 & pH 6 \\
\hline \multicolumn{5}{|l|}{ Spray drying } \\
\hline \multirow{2}{*}{ MAS } & $158.9^{\mathrm{cA}} \pm 9.7$ & $163.2^{\mathrm{cA}} \pm 20.0$ & $189.4^{\mathrm{bB}} \pm 6.9$ & $215.6^{\mathrm{bC}} \pm 6.3$ \\
\hline & $\mathrm{t}_{1 / 2}=4.3$ & $\mathrm{t}_{1 / 2}=4.2$ & $\mathrm{t}_{1 / 2}=3.6$ & $\mathrm{t}_{1 / 2}=3.2$ \\
\hline \multirow{2}{*}{ MXS } & $127.3^{\mathrm{bA}} \pm 11.9$ & $119.1^{\mathrm{bA}} \pm 5.6$ & $108.4^{\mathrm{aA}} \pm 1.6$ & $118.8^{\mathrm{aA}} \pm 5.7$ \\
\hline & $\mathrm{t}_{1 / 2}=5.4$ & $\mathrm{t}_{1 / 2}=5.8$ & $t_{1 / 2}=6.3$ & $\mathrm{t}_{1 / 2}=5.8$ \\
\hline \multicolumn{5}{|l|}{ Freeze drying } \\
\hline \multirow{2}{*}{ MAL } & $118.4^{\mathrm{bA}} \pm 13.0$ & $121.6^{\mathrm{bA}} \pm 1.4$ & $110.6^{\mathrm{aA}} \pm 2.9$ & $126.0^{\mathrm{aA}} \pm 4.0$ \\
\hline & $\mathrm{t}_{1 / 2}=5.8$ & $\mathrm{t}_{1 / 2}=5.7$ & $t_{1 / 2}=6.2$ & $\mathrm{t}_{1 / 2}=5.5$ \\
\hline \multirow{2}{*}{ MXL } & $91.3^{\mathrm{aA}} \pm 4.9$ & $91.8^{\mathrm{aA}} \pm 1.9$ & $105.7^{\mathrm{aA}} \pm 4.0$ & $101.4^{\mathrm{aA}} \pm 4.9$ \\
\hline & $\mathrm{t}_{1 / 2}=7.6$ & $t_{1 / 2}=7.5$ & $t_{1 / 2}=6.5$ & $\mathrm{t}_{1 / 2}=6.8$ \\
\hline
\end{tabular}

Different lowercase letters in the same column (considering the samples) and different capital letters in the same line (considering the evaluated $\mathrm{pHs}$ ) are significantly different statistically $(\mathrm{p}<0.05)$. 
obtained half-lives ranging from 1.6 to 2.5 days at different $\mathrm{pHs}$, lower values by comparing with our study.

\subsection{Color parameters and phenolic compounds of the microcapsules in buffer solutions}

Phenolic compounds content and color parameters $\left(\mathrm{L}^{*}, \mathrm{a}^{*}, \mathrm{~b}^{*}\right)$ in $\mathrm{pH} 3,4,5$ and 6 were determined in day zero $\left(\mathrm{t}_{0}\right)$ and after 7 days of storage at $30^{\circ} \mathrm{C}\left(\mathrm{t}_{7}\right)$. Results (Table 2) demonstrate that, at $\mathrm{pH} 4$, no significant reduction was observed in phenolic content of any microcapsules after 7 storage days at $30^{\circ} \mathrm{C}$. The microcapsules containing maltodextrin and xanthan gum, dried by spray drying and freeze drying, showed greater variation in phenolic content at $\mathrm{pH} 3,5$ and 6, being more significant for the microcapsules dried by spray drying.

An interesting trend was observed by comparing the results of betanin content with the results of phenolic content of red beet extract microcapsules stored at $30^{\circ} \mathrm{C}$, in different buffer solutions: the degradation of betanin was more significant than the degradation of phenolic compounds. It is important to highlight that betanins are the major phenolic compounds present in red beet, therefore it was expected that the rate of betanin degradation would be consistent with the degradation rate measured for all phenolic compounds. However, this result was also observed by Kujala et al. (2000) that evaluated the betacyanin content and the phenolic content of red beet, stored at low temperatures, they reported that most variation in betanin content of red beet extract is due to poor stability of the compound, even though it was encapsulated and not all betanin degradation products are phenolic.

After 7 storage days the $\mathrm{a}^{*}$ parameter was reduced in all samples, the smallest reduction was observed at $\mathrm{pH} 3$, where $\mathrm{a}^{*}$ decreased $78.17 \%$ in the MAS sample, and $65.58 \%$ for sample MAL, followed by MXL sample with $54.99 \%$ and $54.52 \%$ for MXS. The addition of xanthan gum in the formation of microcapsules increased the stability of betanin during storage and buffering

Table 2. Content of phenolic compounds and color parameters of the microcapsule solutions at varying pHs.

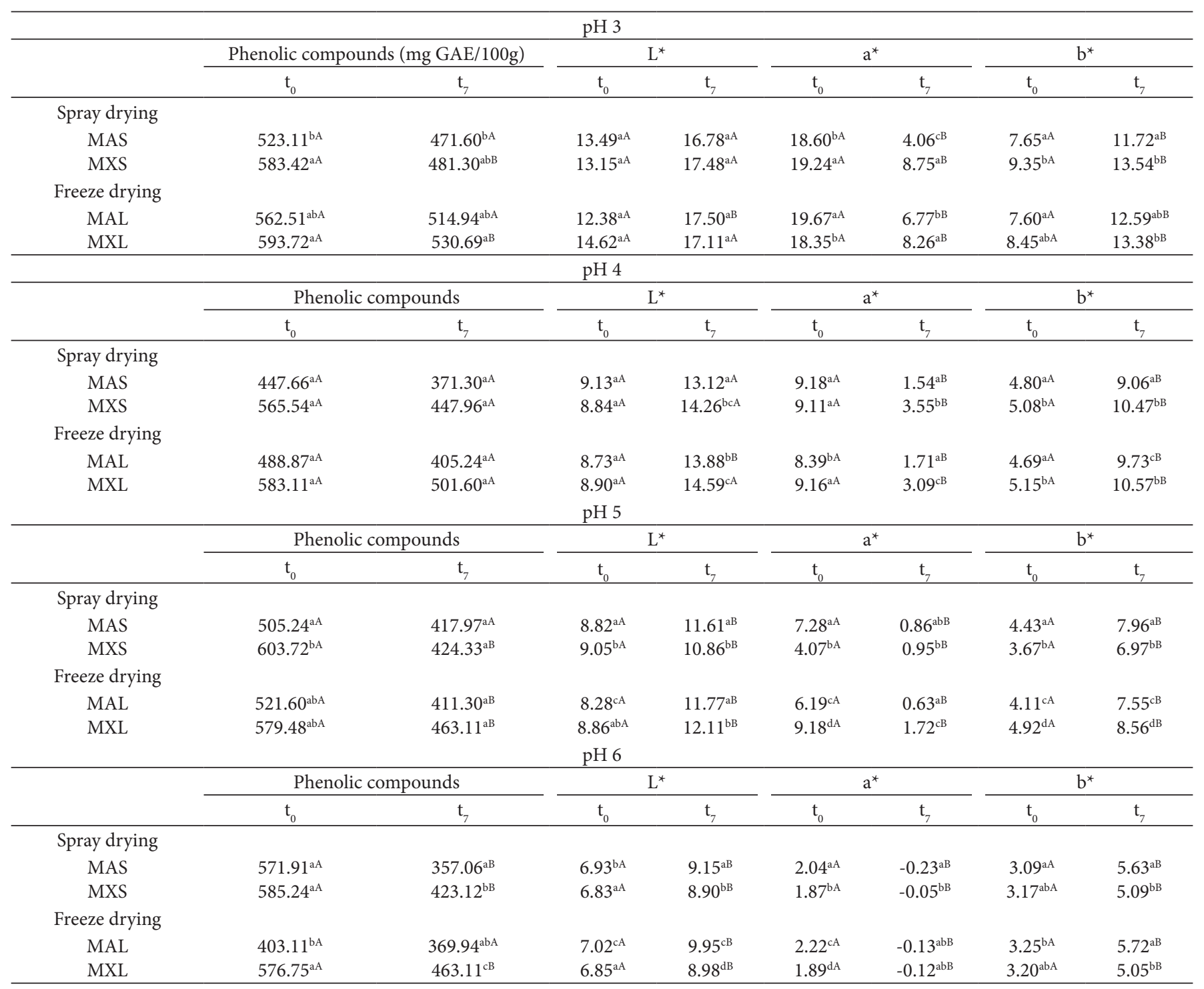

Different lowercase letters in the same column, and different capital letters on the same line differ statistically $(\mathrm{p}<0.05)$. 
Table 3. Pearson coefficients for microcapsules produced with maltodextrin and xanthan gum by spray drying and immersed in a pH 3 solution.

\begin{tabular}{ccccccc}
\hline & Betanin & Phenolic compounds & $\mathrm{L}^{*}$ & $\mathrm{a}^{*}$ & $\mathrm{~b}^{*}$ & \multicolumn{2}{c}{$\mathrm{h}$} \\
\hline Betanin & - & 0.907 & -0.926 & 0.993 & -0.841 & -0.918 \\
Phenolic compounds & 0.907 & - & -0.991 & 0.946 & -0.988 & -0.996 \\
$\mathrm{~L}^{*}$ & -0.926 & -0.991 & - & -0.960 & 0.977 & 0.992 \\
$\mathrm{a}^{*}$ & 0.993 & 0.946 & -0.960 & - & -0.896 & -0.957 \\
$\mathrm{~b}^{*}$ & -0.841 & -0.988 & 0.977 & -0.896 & - & 0.985 \\
$\mathrm{~h}$ & -0.918 & -0.996 & 0.992 & -0.957 & 0.985 & - \\
\hline
\end{tabular}

with a lower reduction of $\mathrm{a}^{*}$ parameter. This result is in agreement with the results of betanin content in the microcapsules where a shorter half life (Table 1) was observed in the sample containing the maltodextrin microcapsules dried by spray drying.

Analyzing the parameter $b^{\star}$ after 7 days, an increase was noticed in all samples, with the greatest increases occurring at $\mathrm{pH}$ 4.The value of $\mathrm{b}^{*}$ increased by $88.75 \%$ for the MAS sample, $105.24 \%$ for the MXL sample, $106.10 \%$ for the MXS sample and $107.46 \%$ for the MAL sample. The degradation of betanin leads to the formation of compounds with a yellow color, as reflected by the significant increase in the $b^{*}$ parameter. The degradation of betanin is usually accompanied by a marked change in color as a result of formation of degradation products with yellow coloring such as betalamic acid, neobetacianins and betaxantins (Herbach et al., 2006).

\subsection{Correlation between betanin content, color parameters and phenolic compounds contents}

Pearson correlation (PC) test was used to evaluate the correlation between betanin contents, color parameters and phenolic compounds content of buffer solutions of microcapsules. All samples of microcapsules showed the same behavior independent of $\mathrm{pH}$, and in general, there was a good correlation Pearson for all parameters ( $\mathrm{CP}>0.8$ ), a 5\% significance level, and as example Table 3 shows the Pearson correlations for the microcapsules produced with maltodextrin and xanthan gum, dried by spray drying and immersed in a pH 3 solution.

The betanin content was significantly correlated with the phenolic compounds in microcapsules, this correlation was positive, since betanin is the main phenolic compound found in red beet. Kujala et al. (2000) also observed a positive Pearson correlation of 0.98 between betanin and total phenolic compounds in the root of red beet (Beta vulgaris), a value close to that found in this study.

The highest Pearson correlation was observed between betanin content and the color parameter $\mathrm{a}^{\star}(0.993)$. This finding can be explained by the fact that betanins produce red coloring, but when they degrade a discoloration of the product occurs resulting in a reduction in the parameter $\mathrm{a}^{*}$.

Although the betanin sample initially has an opaque red color, during the process of degradation the color changes to a clearer yellow, which leads to an increase in the parameters $b^{*}$ and $L^{*}$. In view of this, the correlation between the betanin content and these parameters is significantly negative. Accordingly, the hue angle $(\mathrm{h})$ also increases, and a negative correlation is also observed between betanin content and the hue angle $(\mathrm{PC}=-0.918)$.
As phenolic compounds have a positive correlation with the betanin content, the same finding is observed when correlates phenolic compounds with color parameters, having a positive coefficient with the parameter $\mathrm{a}^{\star}(0.946)$ and negative with the parameters $b^{*}, L^{*}$ and $h(P C=-0.991, P C=-0.988, P C=-0.996$, respectively).

\section{Conclusion}

In general, all microcapsules evaluated, except the MAS, showed good encapsulation efficiency because, although degradation of the dye occurred, this degradation was independent of $\mathrm{pH}$. Microcapsules produced using the combination of maltodextrin and xanthan gum and drying by freeze drying, showed the lowest degradation constant $(\mathrm{k})$ and the longest half-life $\left(\mathrm{t}_{1 / 2}\right)$.Thus, the best samples suggested for use in food products at $\mathrm{pH} 3$ to 6 is sample MXL, after MAL and MXS.

The greatest variation in phenolic content during storage was observed in the microcapsules containing maltodextrin and xanthan gum, dried by spray drying. The parameter $\mathrm{a}^{*}$ decreased with storage time and the parameters $\mathrm{b}^{\star}$ and $\mathrm{L}^{\star}$ increased during storage for all samples, due to degradation of the red color of betanins and the resulting formation of new compounds that were a lighter yellow color. Finally, we conclude that microencapsulation by freeze and spray drying using maltodextrin and xanthan gum as encapsulating agents, may be suitable for use as a color stabilizer for red beet extracts.

\section{References}

Bustos-Garza, C., Yáñez-Fernández, J., \& Barragán-Huerta, B. E. (2013). Thermal and $\mathrm{pH}$ stability of spray-dried encapsulated astaxanthin oleoresin from Haematococcus pluvialis using several encapsulation wall materials. Food Research International, 54(1), 641-649. http:// dx.doi.org/10.1016/j.foodres.2013.07.061.

Cano-Higuita, D. M., Malacrida, C. R., \& Telis, V. R. N. (2015). Stability of curcumin microencapsulated by spray and freeze drying in binary and ternary matrices of maltodextrin, Arabic gum and modified starch. Journal of Food Processing and Preservation, 39(6), 2049-2060. http://dx.doi.org/10.1111/jfpp.12448.

Cardoso-Ugarte, G. A., Sosa-Morales, M. E., Ballard, T., Liceaga, A., \& San Martín-González, M. F. (2014). Microwave-assisted extraction of betalains from red beet (Beta vulgaris). LWT-Food Science and Technology, 59(1), 276-282. http://dx.doi.org/10.1016/j.lwt.2014.05.025.

Gandía-Herrero, F., Escribano, J., \& García-Carmona, F. (2009). The role of phenolic hydroxy groups in the free radical scavenging activity of betalains. Journal of Natural Products, 72(6), 1142-1146. PMid:19456119. http://dx.doi.org/10.1021/np900131r. 
Herbach, K. M., Stintzing, F. C., \& Carle, R. (2006). Betalain stability and degradation: structural and chromatic aspects. Journal of Food Science, 71(4), 41-50. http://dx.doi.org/10.1111/j.1750-3841.2006.00022.x.

Huang, A. S., \& Von Elbe, J. H. (1987). Effect of $\mathrm{pH}$ on the degradation and regeneration of betanin. Journal of Food Science, 52(6), 16891693. http://dx.doi.org/10.1111/j.1365-2621.1987.tb05907.x.

Janiszewska, E. (2014). Microencapsulated beetroot juice as a potential source of betalain. Powder Technology, 264, 190-196. http://dx.doi. org/10.1016/j.powtec.2014.05.032.

Kirca, A., \& Cemeroglu, B. (2003). Degradation kinetics of anthocyanins in blood orange juice and concentrate. Food Chemistry, 81(4), 583587. http://dx.doi.org/10.1016/S0308-8146(02)00500-9.

Kujala, T. S., Loponen, J. M., Klika, K. D., \& Pihlaja, K. (2000). Phenolics and betacyanins in red beetroot (Beta vulgaris) root: distribution and effect of cold storage on the content of total phenolics and three individual compounds. Journal of Agricultural and Food Chemistry, 48(11), 5338-5342. PMid:11087483. http://dx.doi.org/10.1021/ jf000523q.

Kumar, P. G., Prashanth, N., \& Kumari, B. C. (2011). Fundamentals and applications of lyophilization. Journal of Advanced Pharmaceutical Research, 2(4), 157-169.

Laohasongkram, K., Mahamaktudsanee, T., \& Chaiwanichsiri, S. (2011). Microencapsulation of macadamia oil by spray drying. Procedia Food Science, 1, 1660-1665. http://dx.doi.org/10.1016/j.profoo.2011.09.245.

Nemzer, B., Pietrzkowski, Z., Spórna, A., Stalica, P., Thresher, W., Michałowski, T., \& Wybraniec, S. (2011). Betalainic and nutritional profiles of pigment-enriched red beet root (Beta vulgaris L.) dried extracts. Food Chemistry, 127(1), 42-53. http://dx.doi.org/10.1016/j. foodchem.2010.12.081.

Poshadri, A., \& Kuna, A. (2010). Microencapsulation technology: a review. Journal of Research ANGRAU, 38(1), 86-102.

Ravichandran, K., Palaniraj, R., Saw, N. M. M. T., Gabr, A. M. M., Ahmed, A. R., Knorr, D., \& Smetanska, I. (2014). Effects of different encapsulation agents and drying process on stability of betalains extract. Journal of Food Science and Technology, 51(9), 2216-2221. PMid:25190886. http://dx.doi.org/10.1007/s13197-012-0728-6.

Ravichandran, K., Saw, N. M. M. T., Mohdaly, A. A. A., Gabr, A. M. M., Kastell, A., Riedel, H., Cai, Z., Knorr, D., \& Smetanska, I. (2013). Impact of processing of red beet on betalain content and antioxidant activity. Food Research International, 50(2), 670-675. http://dx.doi. org/10.1016/j.foodres.2011.07.002.

Ruiz-Gutiérrez, M. G., Amaya-Guerra, C. A., Quintero-Ramos, A., Ruiz-Anchondo, T. J., Gutiérrez-Uribe, J. A., Báez-González, J. G., Lardizabal-Gutiérrez, D., \& Campos-Venegas, K. (2014). Effect of soluble fiber on the physicochemical properties of cactus pear (Opuntia ficus indica) encapsulated using spray drying. Food Science and Biotechnology, 23(3), 755-763. http://dx.doi.org/10.1007/ s10068-014-0102-8.

Saénz, C., Tapia, S., Chavez, J., \& Robert, P. (2009). Microencapsulation by spray drying of bioactive compounds from cactus pear (Opuntia ficus indica). Food Chemistry, 114(2), 616-622. http://dx.doi. org/10.1016/j.foodchem.2008.09.095.

Serris, G. S., \& Biliaderis, C. G. (2001). Degradation kinetics of beetroot pigment encapsulated in polymeric matrices. Journal of the Science of Food and Agriculture, 81(8), 691-700. http://dx.doi.org/10.1002/ jsfa.864.

Stintzing, F. C., Herbach, K. M., Mosshammer, M. R., Carle, R., Yi, W., Sellappan, S., Akoh, C. C., Bunch, R., \& Felker, P. (2005). Color, betalain pattern, and antioxidant properties of cactus pear (Opuntia spp.) clones. Journal of Agricultural and Food Chemistry, 53(2), 442451. PMid:15656686. http://dx.doi.org/10.1021/jf048751y.

Straus, S., Bavec, F., Turinek, M., Slatnar, A., Rozman, C., \& Bavec, M. (2012). Nutritional value and economic feasibility of red beetroot (Beta vulgaris L. ssp. vulgaris Rote Kugel) from different production systems. African Journal of Agricultural Research, 7(42), 5653-5660. http://dx.doi.org/10.5897/AJAR12.1519. 